[Agr. Biol. Chem., Vol. 27, No. 4, p. 259 264, 1963]

\title{
Lipids of Algae
}

\section{Part IV. Carotenoid Pigments of Scenedesmus}

\author{
By Ihei Iwata and Yosito Sakurai* \\ The Laboratory of Food and Nutrition of Japan Women's University, Tokyo \\ *Department of Agricultural Chemistry, Faculty of Agriculture, University of Tokyo
}

Received November 26, 1962

\begin{abstract}
The carotenoid pigments prepared from methanol and ether extracts from Scenedesmus were separated into epiphasic, midphasic and hypophasic fractions by partition between petroleum ether and $90 \%$ methanol. Each fraction was subjected to column chromatography, using aluminium oxide, magnesium oxide, calcium hydroxide and calcium carbonate as adsorbent. The absorption maxima of the separated pigments in hexane and carbon disulfide were compared with those of the known pigments. Some of them were identified as those previously known, which are as follows: $a$-carotene, $\beta$-carotene, polycis-lycopene VI, astacin, lutein, lutein-5,6-epoxide, antheraxanthin, taraxanthin, violaxanthin, astaxanthin and neoxanthin.
\end{abstract}

The authors had previously examined the carotenoid pigments from Chlorella ${ }^{1)}$. This paper deals with those from Scenedesmus. $\beta$-Carotene, lutein and fucoxanthin are most widely distributed in algae, but fucoxanthin is absent from Chlorella vulgaris ${ }^{2}$. Other than those carotenoid pigments a-carotene, violaxanthin, taraxanthin and etc. were also found in some algae $e^{2,3)}$. U. Blass et al.4) studied on biosynthesis and possible functional relationships among the carotenoids, and assumed that one of the carotenoid pigments from Scenedesmus was antheraxanthin.

\section{EXPERIMENTAL}

1. Material. A fresh cake of Scenedesmus cells prepared at the Micro-algae Research Institute of

1) I. Iwata, H. Nakata and Y. Sakurai, This Journal, 25, 377 (1961).

2) T.W. Goodwin, "The Comparative Biochemistry of the Carotenoids", Chapman and Hall Ltd., London (1952).

3) K. Paech and M.V. Tracey, "Moderne Methoden der Pflanzenanalyse", 3 Band, Springer, Berlin (1955).

4) U. Blass, J.M. Anderson and M. Calvin, Plant Physiol., 34, 329 (1959).
Japan in Dec. 1960 was used.

2. Extraction and Partition of the Pigments. The outline of the extraction and partition is shown in Fig. 1.

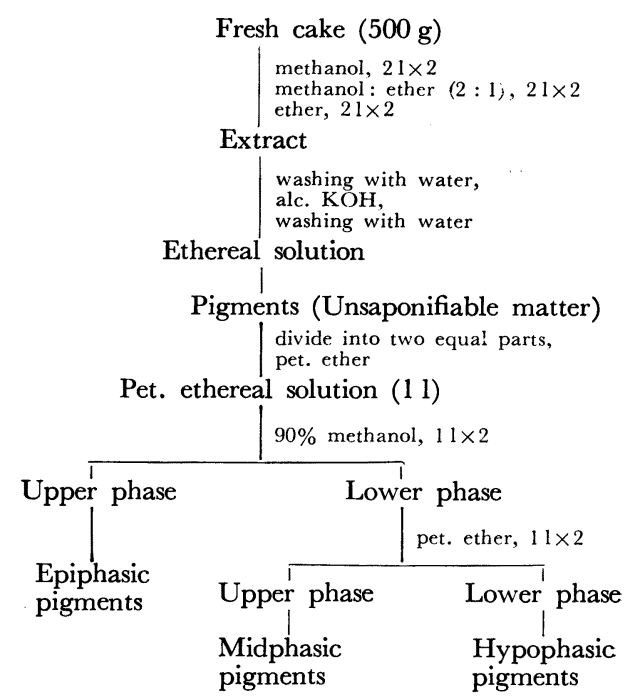

Fig. 1. Extraction and Partition of the Pigments. 
Extraction of the Pigments. The fresh cake was separated from the nutrient medium by centrifugation, and $500 \mathrm{~g}$ of the medium free cake was immersed in 21 methanol. The mixture was stirred for thirty minutes at room temperature, and filtered on Buchner funnel by adding a suitable amount of ether to aid filtration. After the methanol-treatment was repeated two times, the residual cells were extracted twice with a methanol-ether (2:1) mixture and twice with ether. All filtrates were combined and the mixture was

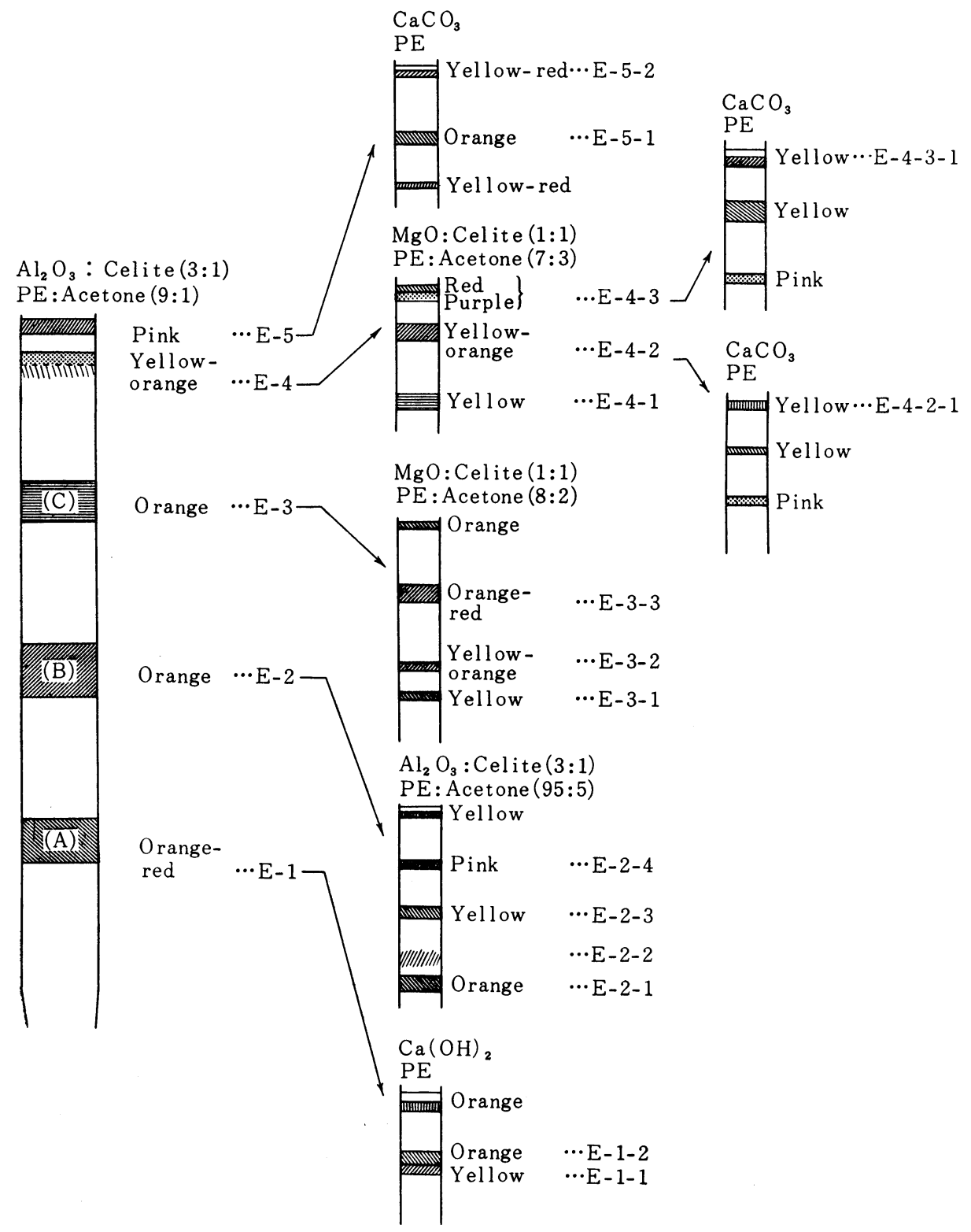

FIG. 2. Chromatographic Separation of Epiphasic Pigments.

Abbreviations: PE, petroleum ether. The ratio of the mixture of adsorbent is shown by weight and that of developer by volume. 
poured into a large amount of water. The upper layer was washed with water and was dried over anhydrous sodium sulfate. Alcoholic potassium hydroxide was added to the ethereal solution, and the mixture was allowed to stand overnight. After saponification, this mixture was washed with a methanol-water (1:2) mixture and water. The ethereal solution was divided into two equal parts and ether was completely removed under reduced pressure in stream of carbon dioxide. One of this residue was used in partition of the $\mathrm{CaCO}_{3}$ $\mathrm{PE}:$ Acetone (95:5)

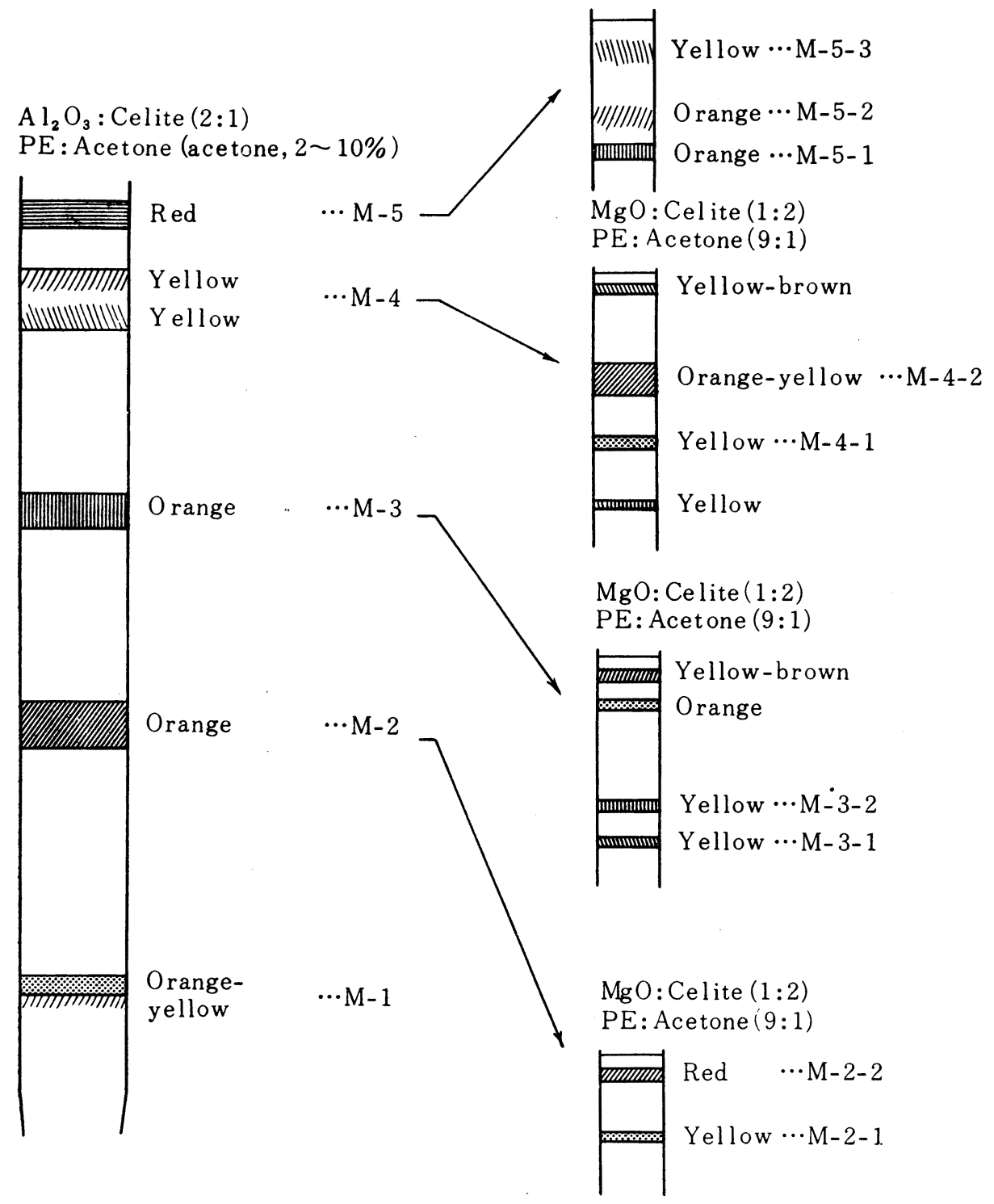

FIG. 3. Chromatographic Separation of Midphasic Pigments. 
pigments.

Partition of the Pigments. The pigments were etxracted five times with $200 \mathrm{ml}$ portions of petroleum ether (b.p. $40 \sim 60^{\circ} \mathrm{C}$ ), and the petroleum ethereal solution was divided into two layers on basis of partition between petroleum ether and $90 \%$ methanol. This partition was repeated two times with 11 portions of $90 \%$ methanol. The upper phase which contains mainly the epiphasic carotenoids was washed with water, dried over sodium sulfate, and concentrated under reduced pressure in stream of car- bon dioxide. The separated epiphasic pigments were subjected to chromatography. The lower aqueous methanolic layer was also divided into two layers on the basis of partition between petroleum ether and $90 \%$ methanol. The upper phase which contains mainly the midphasic carotenoids, almost equally distributed between epiphase and hypophase, was treated with the same manner as in epiphase and the separated carotenoids were subjected to chromatography. The lower aqueous methanolic phase which contains mainly the hypophasic carotenoids was diluted with water

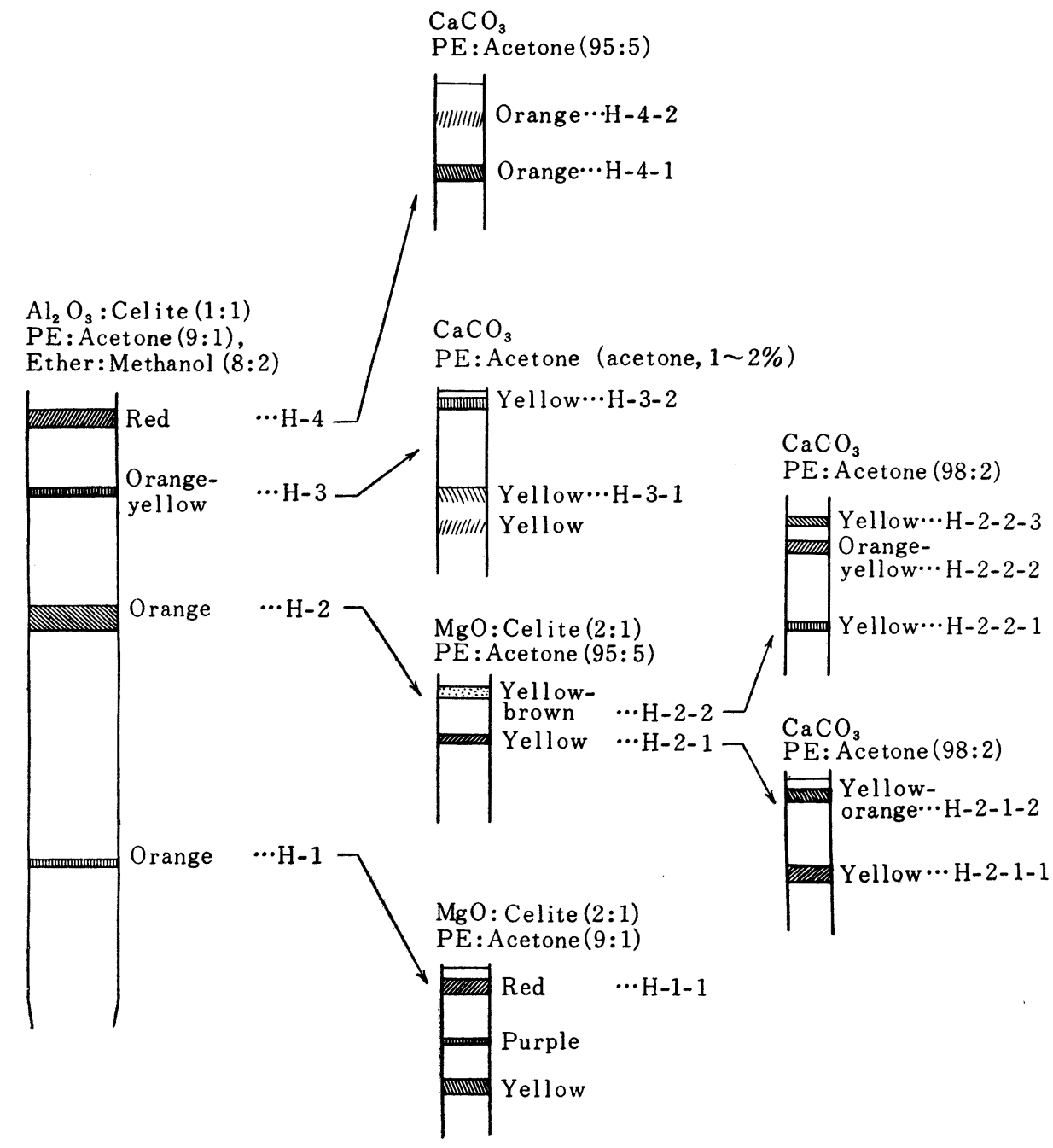

FIG. 4. Chromatographic Separation of Hypophasic Pigments.

Abbreviations are the same as those shown in Fig. 2. 
and was extracted with ether. After washing and drying of the ethereal solution, ether was completely removed under reduced pressure in the current of carbon dioxide. The hypophasic pigments thus obtained were subjected to chromatography.

3. Chromatographic Separation of the Pigments. The chromatograms of the epiphasic, midphasic and hypophasic pigments are shown in Figs. 2, 3 and 4. In the first chromatographic separation of each fraction, $5 \times 40 \mathrm{~cm}$ tube was used. In the second and later separations, $2 \times 20$ or $2.5 \times 40 \mathrm{~cm}$ tube was used. The adsorbents and the developer were selected as shown in the Figures, and the separated pigments were numbered.

Epiphasic Pigments. In the first chromatographic separation, all the pigments were adsorbed near the top of the column and were developed with a petroleum ether and acetone (9:1) mixture. The chromatogram with six coloured zones was obtained. After the first fraction (A) had been eluted, the development was stopped when the frontal edge of the decending fraction $B$ came near the bottom of the column. Then the coloured zones in the column were removed from the tube and the each zone was mechanically divided. The pigments of each zone were eluted and again subjected to chromatography.

Midphasic Pigments. In the first chromatographic separation, all the pigments were adsorbed near the top of the column, and were developed with petroleum ether containing $2 \%$ acetone at first. Subsequently the first coloured zone (M-1) was eluted with petroleum ether containing $5 \%$ acetone, and the developer was replaced with petroleum ether containing $10 \%$ acetone. Each coloured zone was treated as epiphasic pigments.

Hypophasic Pigments. Hypophasic pigments were dissolved with petroleum ether and petroleum ether containing $10 \%$ acetone. After the first coloured zone (H-1) was eluted with petroleum ether containing $10 \%$ acetone, the developer was replaced with ether containing $20 \%$ methanol. Each coloured zone was treated as before.

4. Measurement of the Absorption Spectrum. The position of the absorption maxima and the shape of the curve measured both in $n$-hexane and in carbon disulfide with photoelectric spectrophotometer were compared with those of the known pigments.

\section{RESULT AND DISCUSSION}

The carotenoids were usually divided into two groups by partition between two immiscible solvents, petroleum ether and $90 \%$ methanol being the usual solvents. Carotenoids with two or more hydroxy groups are thus obtained as hypophasic pigments and those without hydroxy groups as epiphasic pigments. Mono-hydroxy compounds occupy an intermediate position and are found in the epiphase as well as in the hypophase. In this experiment, the carotenoids were divided into three fractions as shown in Fig. 1. The midphase fraction by this procedure was expected to contain those pigments distributed in epiphase as well as in hypophase by the previous procedure. The pigments separated from each fraction gave a characteristic absorption spectrum, its absorption maxima are shown in Tables I, II and III. The pigments, of which the absorption maxima were in good

TABle I. THE ABsorption MAXiMA OF EPIPIGMENTS PHASIC

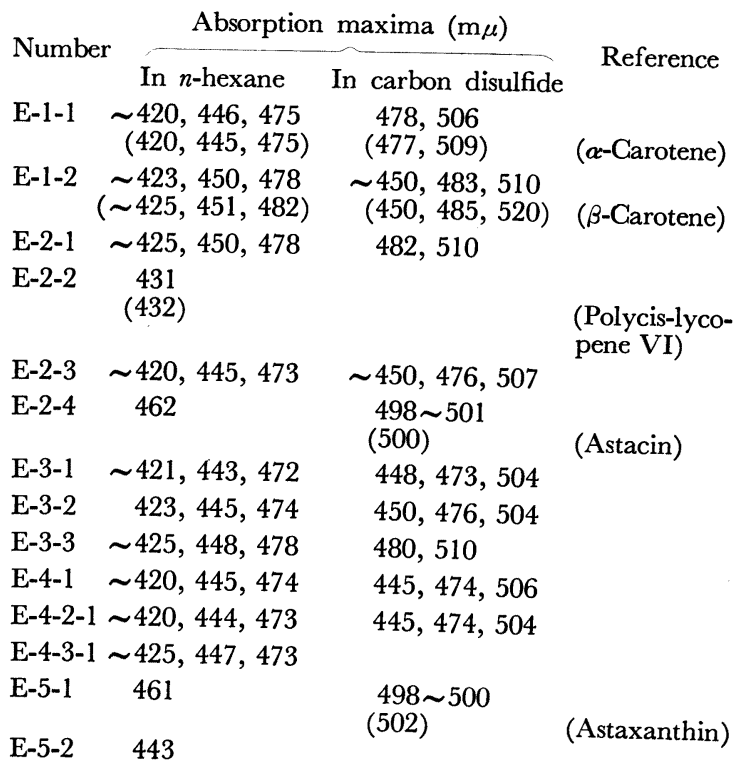

"Data in parentheses are from: K. Paech and M.V. Tracey "Moderne Methoden der Pflanzenanalyse" 3 Band, Springer, Berlin

$\sim$ indicates an inflection. 
TABLE II. THE ABSORPtion MAXIMA OF MIDPHASIC PIGMENTS

\begin{tabular}{|c|c|c|c|}
\hline \multirow{2}{*}{ Number } & \multicolumn{2}{|c|}{ Absorption maxima $(\mathrm{m} \mu)$} & \multirow{2}{*}{ Reference } \\
\hline & In $n$-hexane & In carbon disulfide & \\
\hline M-1 & $\sim 425,450,478$ & $\sim 450,483,509$ & \\
\hline M-2-1 & $422,445,473$ & $\sim 450,475,506$ & \\
\hline M-2-2 & 463 & $\begin{array}{c}500 \\
(500)\end{array}$ & (Astacin) \\
\hline M-3-1 & $\begin{array}{c}423,446,476 \\
(420,447,477)\end{array}$ & $\begin{array}{c}445,475,506 \\
(445,475,508)\end{array}$ & (Lutein) \\
\hline M-3-2 & $\begin{array}{l}\sim 424,443,473 \\
(442,471)\end{array}$ & $\begin{array}{l}\sim 445,471,503 \\
\quad(472,502)\end{array}$ & $\begin{array}{l}\text { (Lutein-5,6- } \\
\text { epoxide) }\end{array}$ \\
\hline M-4-1 & $\begin{array}{l}420,443,473 \\
(443,472)\end{array}$ & $\begin{array}{c}443,470,502 \\
(441,469,501)\end{array}$ & (Taraxanthin) \\
\hline M-4-2 & $\begin{array}{l}420,443,473 \\
(443,472)\end{array}$ & $\begin{array}{c}443,472,502 \\
(440,470,501)\end{array}$ & (Violaxanthin) \\
\hline M-5-1 & 462 & $\begin{array}{l}498 \sim 503 \\
(502)\end{array}$ & (Astaxanthin) \\
\hline $\begin{array}{l}\text { M-5-2 } \\
\text { M-5-3 }\end{array}$ & $\begin{array}{l}455 \\
411,436,465 \\
(437,466)\end{array}$ & $\begin{array}{l}495 \\
440,464,494 \\
(463,493)\end{array}$ & (Neoxanthin) \\
\hline
\end{tabular}

TABle III. THE ABSORPTION MAXIMA OF HYPOPHASIC PIGMENTS

\begin{tabular}{|c|c|c|c|}
\hline \multirow{2}{*}{ Number } & \multicolumn{2}{|c|}{ Absorption maxima $(\mathrm{m} \mu)$} & \multirow{2}{*}{ Reference } \\
\hline & In $n$-hexane & In carban disulfide & \\
\hline H-1-1 & 463 & $\begin{array}{c}500 \\
(500)\end{array}$ & (Astacin) \\
\hline H-2-1-1 & $\begin{array}{c}423,446,476 \\
(420,447,477)\end{array}$ & $\begin{array}{c}445,474,507 \\
(445,475,508)\end{array}$ & (Lutein) \\
\hline $\mathrm{H}-2-1-2$ & $\begin{array}{c}\sim 423,442,472 \\
(442,471)\end{array}$ & $\begin{array}{l}\sim 445,472,502 \\
\quad(472,502)\end{array}$ & (lutein-5,6- \\
\hline H-2-2-1 & $\sim 420,443,473$ & $444,470,503$ & \\
\hline H-2-2-2 & $\sim 425,447,473$ & $\begin{array}{l}\sim 450,477,510 \\
(478,510)\end{array}$ & $\begin{array}{l}\text { (Antherax- } \\
\text { anthin) }\end{array}$ \\
\hline H-2-2-3 & $\begin{array}{l}\sim 410,437,466 \\
(437,466)\end{array}$ & $\begin{array}{c}\sim 440,463,494 \\
(463,493)\end{array}$ & (Neoxanthin) \\
\hline H-3-1 & $\begin{array}{l}\sim 420,444,473 \\
\quad(443,472)\end{array}$ & $\begin{array}{r}\sim 440,472,502 \\
(441,469,501)\end{array}$ & (Taraxanthin) \\
\hline $\mathrm{H}-3-2$ & $\begin{array}{l}\sim 420,442,472 \\
\quad(443,472)\end{array}$ & $\begin{array}{r}\sim 440,472,501 \\
\quad(440,470,501)\end{array}$ & (Violaxanthin) \\
\hline H-4-1 & $458 \sim 464$ & $\begin{array}{c}502 \\
(502)\end{array}$ & (Astaxanthin) \\
\hline $\mathrm{H}-4-2$ & 455 & 495 & \\
\hline
\end{tabular}

agreement with those recorded in the references, were as follows: $a$-carotene, $\beta$-carotene, polycis-lycopene VI, astacin, lutein, lutein-5,6epoxide, antheraxanthin, taraxanthin, viola xanthin, astaxanthin and neoxanthin. In the first chromatographic separation of epiphasic pigments, carotene was easily developed and gave the most deeply coloured zone. The colourless eluate running before the first coloured zone (A) gave a small amount of oily liquid and was assumed to be a hydrocarbon by its absorption pattern in infrared region, but the colourless polyene was not found. The coloured zones near the top of the column were very faintly coloured. The chromatograms of midphasic and hypophasic pigments seem to be similar to those of epiphasic pigments, but the coloured zone near the bottom of the column was very faintly coloured and carotene was not found at all in hypophase. E-2-4 was identified with M-2-2 and H-1-1 by the mixed chromatography, and its absorption maximum was in good agreement with that of astacin. E-5-1 was also identified with M-5-1 and H-4-1, and its absorption maximum was in good agreement with that of astaxanthin. The first fraction of midphasic pigments (M-1) was assumed to be carotene but further separation was not performed. Those pigments examined their identities by mixed chromatography were: lutein, lutein-5,6-epoxide, taraxanthin, violaxanthin and neoxanthin in midphase and hypophase.

In the previous paper ${ }^{1)}$, the pigments of which the absorption maxima were in good agreement with those of rhodoxanthin and sarcinaxanthin were separated from Chlorella, though those were not obtained from Scenedesmus.

Acknowledgement. The authors wish to express their gratitude to the Micro-algae Research Institute of Japan for the samples. The authors were indebted to Mr. K. Aizawa for help in the infrared spectrophotometric measurement and also to Miss Akiko Hatanaka for her generous assistance in the course of these experiments. 